Anaesthesist $2015 \cdot[$ Suppl 1] 64:S27-S40

DOI 10.1007/s00101-015-0109-4

Published online: 4 January 2016

๑) Springer-Verlag Berlin Heidelberg 2015

CrossMark

T. Piepho ${ }^{1}$ E. Cavus ${ }^{2} \cdot$ R. Noppens ${ }^{1} \cdot$ C. Byhahn ${ }^{3} \cdot$ V. Dörges ${ }^{2}$ B. Zwissler ${ }^{4,5}$. A. Timmermann ${ }^{6}$

${ }^{1}$ Department of Anesthesiology, University Medical Center of the

Johannes Gutenberg-University-Mainz, Mainz, Germany

${ }^{2}$ Department of Anesthesiology and Surgical Intensive Care, University

Medical Center Schleswig-Holstein, Kiel, Germany

${ }^{3}$ Department of Anesthesiology, Intensive Care Medicine and Pain Therapy, Medical Campus

University Oldenburg, Evangelical Hospital Oldenburg, Oldenburg, Germany

${ }^{4}$ Department of Anesthesiology, Ludwig-Maximilian University Clinic Munich, Munich, Germany

${ }^{5}$ Department of Anesthesiology, Ludwig-Maximilians-University, Munich, Germany

${ }^{6}$ Department of Anesthesiology, Pain Therapy, Intensive Care Medicine and Emergency

Medicine, German Red Cross Hospitals Berlin Westend and Mitte, Berlin, Germany

\title{
S1 guidelines on airway management
}

\section{Guideline of the German Society of Anesthesiology and Intensive Care Medicine}

important contribution to a reduction in morbidity and mortality.

The first German "guidelines on airway management" were approved by the German Society for Anesthesiology and Intensive Care Medicine (DGAI) in the year 2004 [1]. Since then new techniques, such as video laryngoscopy have become established in everyday clinical practice. Additionally, new findings have been published on already existing strategies. The new German "guidelines on airway management" necessarily reflect the current state of science and integrate currently recommended techniques and strategies. These guidelines for airway management are intended to contribute to ensuring optimum care for patients undergoing anesthesiological procedures. They are also intended to serve as an orientation and decision-making aid for physicians who manage airways in daily practice. For many of the following recommendations on practical procedures and/or on the use of particular techniques there is a lack of highquality, qualitative clinical studies; therefore, these guidelines represent the consensus of an expert group corresponding to level S1 of the classification levels of the Association of the Scientific Medical Soci- eties in Germany (AWMF, Arbeitsgemeinschaft der Wissenschaftlichen Medizinischen Fachgesellschaften e. $V$., see www.awmf. org) (•Infobox 1).

\section{Definition, predictors and incidence of difficult airways}

\section{Definitions}

The term "difficult airway" incorporates several problems that can appear during airway management. Regardless of the improvements in techniques for airway management, for example, by means of video laryngoscopy and rigid or flexible endoscopy, the definitions of the difficult airway still follow the two traditional techniques of mask ventilation and intubation assisted by direct laryngoscopy. A prerequisite for specialist qualification for such procedures is the specialist standard in anesthesiology. All recommendations relate to the minimum qualification of a specialist anesthesiologist and assume sufficient experience in the routine application of each particular technique.

Ventilation with the aid of a face mask or an extraglottic airway device (EGA, for the definition see the section "techniques 
Infobox 1: Introduction to these guidelines

\section{Administrative specialist group}

German Society for Anesthesiology and In-

tensive Care Medicine (DGAl)

AWMF register nr.: 001/028

Next revision planned 11 March 2020

\section{Consensus classification}

Statements and recommendations were resolved as the consensus of experts within the guidelines group. The strength of the consensus is made evident by the formulation used (shall/should/can) and corresponds to the classification given in $\bullet$ Table 7.

\section{Special note}

The practice of medicine is subject to a continuous developmental process and therefore, all information, in particular that regarding diagnostic and therapeutic methods, can only ever reflect the current state of knowledge at the time of publication of the guidelines. The greatest caution was exercised with respect to the recommendations given on therapy and the selection as well as dosage of medications.

The individual user must bear the responsibility for any diagnostic and therapeutic applications, medications and dosage. For out of hospital airway management [2], treatment of multiple trauma [3] and pediatric anesthesia [4], the existing treatment recommendations and guidelines should be referred to. These guidelines use registered trademarks (protected product names) without designating them as such. Thus the absence of any corresponding reference does not mean that it pertains to an unprotected product name.

for airway management") is defined as being difficult or impossible if, owing to one or more problems, ventilation is insufficient or even fails completely due to, for example faulty seals, massive leakage and resistance during inspiration or expiration.

Placement of an EGA is defined as difficult when multiple placement attempts are needed. A difficult laryngoscopy is defined as the impossibility to visualize the glottis with the aid of direct laryngoscopy. This corresponds to Cormack and Lehane grades III and IV ([5], • Fig. 4).

A difficult endotracheal intubation is present when multiple intubation attempts are required.

\section{Incidence of difficult airways}

The precise determination of the incidence of difficult mask ventilation, laryngoscopy or intubation has so far not been possible as the definition of a difficult airway has not been consistent between the various studies. Likewise, possible interindividual differences in the practical skills of the investigators have to be taken into account. Here too, the standard of a specialist anesthesiologist only provides an imprecise definition of competency. Thus it is possible and even likely that different working groups will report different results even for identical groups of patients. This problem must always be taken into account in the interpretation of such clinical studies.

\section{Incidence of difficult mask ventilation}

If the results of several authors with large groups of patients are summarized irrespective of the various divergent definitions, the incidence of difficult mask ventilation in an unselected group of elective patients is $2 \%$ [6-8]. The incidence of impossible mask ventilation is $0.15 \%(1: 670)$ [6].

\section{Incidence of difficult laryngoscopy and intubation}

Problems during endotracheal intubation are frequently combined under the term "difficult intubation" without differentiating between laryngoscopic and endotracheal intubation. This vagueness is of subordinate importance as in direct laryngoscopy the anatomical and optical axes converge and thus in the case of acceptable results of laryngoscopy a successful placement of the tube can also be expected; however, if techniques for indirect laryngoscopy (for definition see section on "techniques for airway management") are used, a clear separation of the two procedures must be made as the incidence of difficult laryngoscopy is always lower than that of the difficult or impossible intubation.

The incidence of difficult direct laryngoscopy is $1.5-8.0 \%$ and the incidence of difficult intubation is slightly lower $[9,10]$. An unexpected "cannot intubate, cannot ventilate" situation is to be expected with a probability between $0.008 \%(1: 13,000)$ and $0.004 \%(1: 25,000)[6,8]$.

\section{Prediction of difficult airways}

Various predictors and screening tests have been described for the detection of a difficult airway. Complications during airway management from prior interventions have proven to be the best predictor of a difficult airway.

\section{Recommendation}

During the preoperative evaluation a query shall be made about any problems which arose during previous anesthesia and the presence of an anesthesia identity card. In addition, as part of the clinical evaluation, predictors for a difficult airway management shall be checked.

\section{Predictors of difficult or impossible mask ventilation}

- Table 1 shows typical predictors for a difficult or impossible mask ventilation [6-8]. The combination of several factors increases the risk of difficult mask ventilation.

Predictors of difficult or impossible direct laryngoscopy and intubation

The most widely used screening instrument is the Mallampati test as modified by Samsoon and Young [11] (• Fig. 5); however, its clinical value as the sole test for prediction of difficult laryngoscopy and intubation is limited. The same also applies to a thyromental distance less than 6-7 cm [12]. Additional test methods, which likewise are less sensitive, comprise the upper lip bite test [13], mobility of the cervical spine, the palm print test $[14,15]$ and the Wilson risk score $[16,17]$. The multifactorial risk index of Arné et al. incorporates seven different criteria [18] so that different predictors are included.

- Table 2 shows typical predictors.

\section{Recommendation}

Owing to the limited predictive value of individual test methods the airway shall be examined for symptoms and predictors which are indicative of a difficult or impossible direct laryngoscopy or intubation. These predictors can be supplemented by a screening test. 


\section{Predictors for difficult indirect laryngoscopy}

So far it has not been possible to identify features or test methods which are predictive for a difficult indirect laryngoscopy, in particular with video-assisted systems. Increased secretion and bleeding in the airways can restrict visibility. A highly limited mouth opening which no longer permits the insertion of the particular video laryngoscope, appears to be the sole predictor at the present time.

\section{Techniques for airway management}

\section{Pre-oxygenation}

\section{Recommendation}

Pre-oxygenation shall always be performed before initiation of general anesthesia for spontaneously breathing patients.

Studies have shown that resorption atelectasis can occur under pre-oxygenation with $100 \%$ oxygen; however, with reduced inspiratory oxygen concentration the $\mathrm{O}_{2}$ reserve can be reduced in the case of difficult airways.

\section{Recommendation}

Depending on the benefit and risks, preoxygenation shall proceed via a tightly fitting facial mask with $100 \%$ oxygen.

Various techniques are possible: 8 maximum deep breaths within $60 \mathrm{~s}$ and preoxygenation for 3-4 min or until the expiratory oxygen concentration exceeds $90 \%$ [19-21].

\section{Recommendation}

A pre-oxygenation shall be implemented with elevated upper body whenever possible $[22,23]$. Use of non-invasive ventilation, e.g. pressure support $8 \mathrm{cmH}_{2} \mathrm{O}$, and positive endexpiratory pressure (PEEP) $5 \mathrm{cmH}_{2} \mathrm{O}$, during pre-oxygenation of patients can improve the apnea tolerance [24, 25].

\section{Mask ventilation}

Mask ventilation is an essential procedure in airway management. It can be imple-

Anaesthesist 2015 - [Suppl 1] 64:S27-S40 DOI 10.1007/s00101-015-0109-4

๑) Springer-Verlag Berlin Heidelberg 2015

T. Piepho · E. Cavus · R. Noppens · C. Byhahn · V. Dörges · B. Zwissler · A. Timmermann S1 guidelines on airway management. Guideline of the German Society of Anesthesiology and Intensive Care Medicine

\section{Abstract}

Since the publication of the first German guidelines on airway management in 2004 new techniques have been established in the clinical routine and new insights into existing strategies have been published. As a consequence the new guidelines on airway management of the German Society of Anesthesiology and Intensive Care Medicine represent the current state of scientific knowledge and integrate the currently recommended techniques and strategies. The aim of these guidelines is to guarantee an optimal care of patients undergoing anesthesiological procedures and serve as an orientation and decision aid for users.

Keywords Airway · Algorithm · Intubation · Extubation . Anesthesia

\section{S1-Leitlinie Atemwegsmanagement. Leitlinie der Deutschen Gesellschaft für Anästhesiologie und Intensivmedizin (DGAI)}

\section{Zusammenfassung}

Seit der ersten deutschen "Leitlinie Atemwegsmanagement" im Jahr 2004 haben sich neue Techniken im klinischen Alltag etabliert, und es wurden neue Erkenntnisse zu bestehenden Strategien publiziert. Konsequenterweise stellt die neue "Leitlinie Atemwegsmanagement" der Deutschen Gesellschaft für Anästhesiologie und Intensivmedizin den aktuellen Stand der Wissenschaft dar und integriert die derzeit empfohlenen Techniken und Strategien. Die vorliegende Leitlinie soll dazu beitragen, eine optimale Versorgung der anästhesiologisch betreuten Patienten zu gewährleisten. Sie soll dem Anwender zur Orientierung und als Entscheidungshilfe dienen.

Schlüsselwörter Atemweg · Algorithmus · Intubation . Extubation · Anästhesie mented manually or with pressure controlled ventilation (PCV).

After induction of general anesthesia most textbooks currently still recommend checking for the feasibility of mask ventilation prior to any neuromuscular block. This dogma, however, has been recently questioned [26, 27]. Several scientific publications have even shown that in most cases mask ventilation is facilitated by a neuromuscular block and was not impeded in any case $[28,29]$.

\section{Recommendation}

In the absence of predictors for difficult airways a neuromuscular blockade can be implemented immediately after achieving a sufficient depth of anesthesia without the possibility of mask ventilation having been previously checked.

\section{Extraglottic airway device}

The term "extraglottic airway device" (EGA) is used to describe all ventilation aids for ensuring that the airway is kept open between the oropharynx and proximal esophagus but outside the glottis. In addition to the different types of laryngeal masks this term also covers the esophageal closing tubes (e.g. laryngeal tube and combitube).

Publications show that under optimum cuff pressure the seal of the EGA is better and comorbidities, such as sore throats are less common [30, 31]. The re-

\section{Recommendation}

After placement and sufficient ventilation the cuff pressure shall be checked and adjusted if necessary. The particular manufacturer's recommendations shall be taken into account. In general a cuff pressure of $60 \mathrm{cmH}_{2} \mathrm{O}$ shall not be exceeded. 


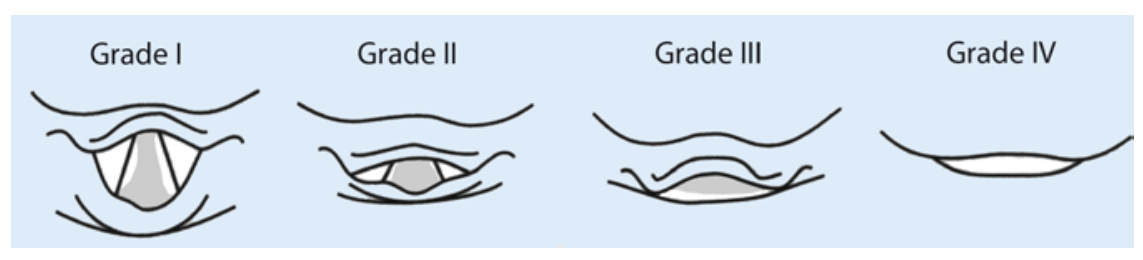

Fig. $4 \Delta$ Laryngoscopic view of the glottis opening according to Cormack and Lehane: grade I full view of glottis, grade II only posterior extremity of glottis seen, grade III only epiglottis and no glottis seen and grade IV neither glottis nor epiglottis seen (reproduced from Heck M, Fresenius M: Klinikmanual Anästhesie, 2. Aufl., Springer, Heidelberg, 2015)
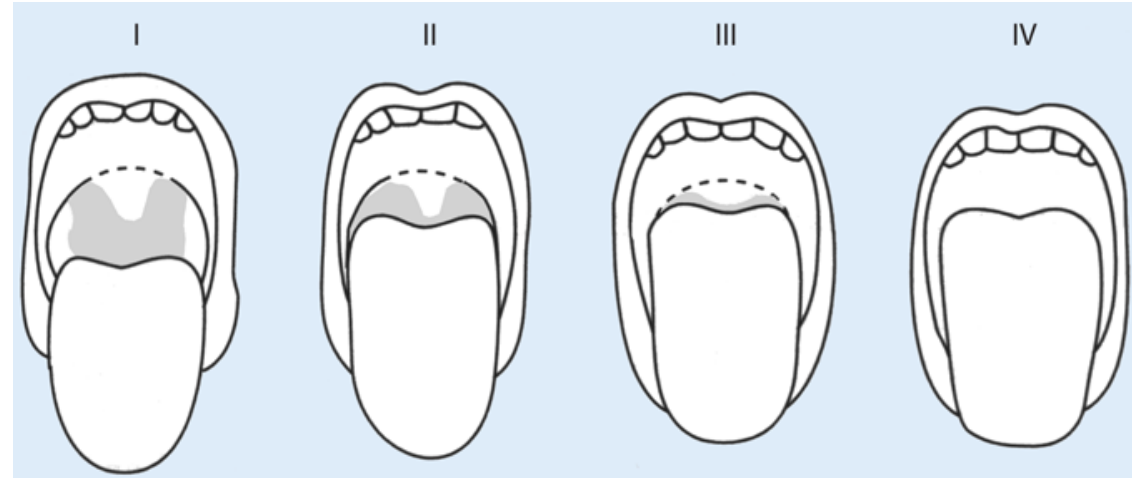

Fig. 5 Mallampati classification as modified by Samsoon and Young for predicting difficult tracheal intubation: Class I: Soft palate, fauces, uvula, pillars visible; Class II: Soft palate and fauces visible, tip of the uvula not visible; Class III: Soft and hard palate visible; Class IV: Soft palate not visible at all (reproduced from Heck M, Fresenius M: Klinikmanual Anästhesie, 2. Aufl., Springer, Heidelberg, 2015)

quired or maximum permissible cuff pressure depends on the selected airway aid and its size.

Second generation EGA devices have an integrated drainage channel through which regurgitated stomach contents can be drained or a gastric tube can be advanced for prophylactic relief. Various tests have been described to check for correct placement of each specific EGA (see - Table 3). The EGA is correctly placed only when the correct insertion depth [32] is achieved, with sufficient ventilation, negative bubble test [33] and correct positioning of the gastric tube after resistance-free insertion.

Different laryngeal masks also allow post-positioning placement of an endotracheal tube. In a 2-step method, in the event of an unexpected difficult airway oxygenation of the patient is first possible via the EGA and subsequently intubation through the EGA can be performed. A blind advancing of the endotracheal tube with a high success rate has only been described for the intubation laryngeal mask airway, which is specifically designed as a guide splint for endotracheal intubation.
If the blind endotracheal intubation fails or if a different EGA is primarily chosen, a flexible intubation endoscope can be used for endotracheal guidance; alternatively an intubation catheter can be initially placed serving as a tracheal guide splint for secondary tube advancement [34-36].

\section{Direct laryngoscopy}

Conventional intubation can be used with the aid of differently shaped blades. In addition to straight (e.g. Miller) and curved blades (e.g. Macintosh) there are other designs, such as the McCoy blade which uses a mobile tip to elevate the epiglottis by means of a lever mechanism.

\section{Indirect laryngoscopy}

The term "indirect laryngoscopy" generally refers to instruments with which direct visualization of the glottis area is not necessary or possible. In principle this can be achieved in two ways: firstly, by use of a small digital camera which transmits images to a monitor (e.g. video laryngoscope, flexible and rigid intubation en- doscopes); secondly, by means of an optical system in which fiberglass tubes (e.g. classical fiber optics) or prisms are used to provide visualization through a lens. By using the lens it is possible to view the image directly or the image can be transmitted by a camera to an external monitor.

\section{Video laryngoscopy}

Due to the integration of a small camera and light source into the blade, the method of video laryngoscopy shifts the user's view from extra-oral into the vicinity of the glottis. Regardless of the shape of the laryngoscope blade used, this technological development alone provides an improved view of the glottis. The view of the glottic area can often be improved with video laryngoscopy if direct laryngoscopy is difficult or even impossible [37-39]; however, despite good visibility, intubation can be delayed and can even fail [40].

The term "video laryngoscopy" nowadays covers a number of devices in which the form, technology and handling sometimes differ fundamentally from each other. One important differentiation criterion for video laryngoscopes is the shape of the blade [41, 42].

\section{Video laryngoscope with Macintosh (or} similar) blade. The great advantage of the Macintosh video laryngoscope is that the user is familiar with the blade shape and can perform a direct laryngoscopy regardless of the video laryngoscopic view on the monitor. In the case of unexpectedly difficult direct laryngoscopy, with this type of blade an indirect visualization of the glottic area can often be achieved. With the aid of this device a sufficient and simplified training in the technique of endotracheal intubation is possible [43].

\section{Video laryngoscope with highly curved}

blade. With a highly curved blade it is not necessary to adjust the oropharyngolaryngeal axis and thus the intubation process will proceed indirectly with an obligatory video laryngoscopic view. The actual difficulty in the intubation using a video laryngoscope with a highly curved blade occurs, in spite of optimum visualization, during the intubation process itself: the tube must be advanced in a steep angle corresponding to the curvature of the 
Table 1 Predictors of difficult or impossible mask ventilation. The risk of difficult or impossible mask ventilation increases with increasing numbers of different predictors or symptoms

Scars, tumors, inflammation, injuries to lips and face

Macroglossia and other pathological changes of the tongue

Radiotherapy or tumor in the neck region

Pathological changes of pharynx, larynx and trachea

Male gender

Age $>55$ years

History of snoring or sleep apnea syndrome

Desolate tooth status, edentulous patients

Full beard

Mallampati grades III and IV

Clearly restricted protrusion of lower jaw, upper lip bite test ${ }^{\mathrm{a}}$

Body mass index $>30 \mathrm{~kg} / \mathrm{m}^{2}$

Thyromental distance $<6 \mathrm{~cm}$

aLower jaw cannot be pushed forward enough to allow contact of teeth or gingiva of the lower jaw with teeth

or gingiva of the upper jaw

Table 2 Predictors of difficult or impossible direct laryngoscopy and intubation. The risk of

difficult or impossible direct laryngoscopy increases with increasing number of different pre-

dictors or symptoms

History of difficult intubation

Stridor

Tumors, abscesses in the head-neck and mediastinal areas

Status after radiotherapy in head-neck area

Status after operation on larynx/pharynx

Prognathism, dysgnathia

Goiter

Macroglossia, e.g. in patients with mucopolysaccharidosis or trisomy 21

Mandibulofacial and maxillofacial dysostosis

Limited mouth opening

Limited neck extension

Reduced thyromental distance

Small or large neck circumference

Subglottic stenosis, tracheal stenosis, tracheal displacement

Sleep apnea syndrome

Pregnancy

Mallampati grades III and IV

Table 3 Tests to check for correct position of an extraglottic airway device with gastric drainage channel

Correct insertion depth

Sufficient ventilation

Bubble test: the gastric drainage channel is filled with a gel and bubbles rising during ventilation indicate that the EGA is not correctly positioned

Resistance-free insertion of a gastric tube and suctioning of stomach contents

blade and the tip of the tube must be lowered after passing the vocal cords. Thus when using this shape of blade a stylet is typically needed and experience outside emergency situations has to be acquired. Avoidance of excessive reclination of the head, a mid-tongue insertion of the blade and careful lifting of the epiglottis can be helpful during the intubation process.

Video laryngoscope with endotracheal guide splint. These systems have a splint located on the laryngoscope blade which is intended to guide the endotracheal tube to the glottis. Similarly to the highly curved blade, all systems of this kind are necessarily indirect laryngoscopes.

\section{Rigid intubation endoscopes}

Rigid intubation endoscopes represent one alternative for intubation of unexpected difficult airways $[44,45]$. In order to successfully employ these instruments in emergency situations, sufficient experience is needed in patients with a normal airway [46].

\section{Flexible intubation endoscopes}

Flexible endoscopic intubation is a commonly used technique for endotracheal intubation, both with unexpected difficult and also with expected difficult airways. The classical device is a fiber-optic endoscope with optical fibers and visualization via a lens. Endoscopes which have a camera chip at the tip of the instrument and transmit the image as an electrical signal to a monitor are becoming increasingly more available.

\section{Translaryngeal and transtracheal techniques}

Management of the airway by means of translaryngeal and transtracheal techniques is the last resort in airway management. These techniques may be necessary both as primary methods, for example, in a supraglottic airway obstruction and also as secondary methods, for example with threatening asphyxia after failed attempts to manage the airway with less invasive techniques.

\section{Cricothyrotomy}

In a cricothyrotomy (synonymous with coniotomy and cricothyroidotomy) procedure the cricothyroid ligament is dissected and a catheter or endotracheal tube is introduced into the airway underneath the glottic area. Three techniques can be distinguished: in the catheter-over-needle technique, puncture of the airway proceeds in a manner comparable to the placement of a permanent peripheral venous catheter. Using Seldinger's technique, after puncture of the trachea with a cannula a guidewire is first introduced and then the catheter is guided via the wire into the trachea. Surgical cricothyrotomy includes the surgical dissection of the cricothyroid ligament using a 
Table 4 Restrictions on use of extraglottic airway devices in patients undergoing elective

interventions

Patients with inflammation, tumors or bleeding in the upper airways which do not allow sufficient placement of an EGA

Mouth opening $<2 \mathrm{~cm}$

Expected ventilation pressures above the individual leakage pressure

Necessity for regular tracheal access

One-lung ventilation

Patients with symptomatic gastroesophageal reflux, symptomatic hiatus, diaphragmatic hernia or

ileus

Interference with surgical access

scalpel after pushing surgical landmarks, such as the thyroid and cricoid cartilages apart and placement of a small diameter endotracheal tube.

Numerous investigations on patients [47], cadavers [48-50] and animal models [51-55] have provided highly contradictory results on the success rate for performing a cricothyrotomy and on the method to be preferred. Both the personal experience of the provider of this last resort of invasive airway management and also the level of medical training are very inhomogeneous and the number of cases is usually very few, so that an evidence-based recommendation of the optimal technique for cricothyrotomy cannot be given. The rate of complications and failure of emergency cricothyrotomy implemented by anesthetists of up to more than $50 \%$ is very high [56].

\section{Tracheotomy}

A tracheotomy can be electively carried out while maintaining spontaneous breathing under local anesthesia. Typical indications are stenotic tumors in the region of the larynx and the hypopharynx.

During an airway emergency surgical tracheotomy can also represent an alternative to cricothyrotomy for a skilled surgeon in selected cases (key word: preparedness for tracheotomy) [57]. The prerequisites are the immediate availability of all necessary surgical material, good ambient conditions (e.g. in an operating room) and excellent routines in order to perform this method in a technically reliable and rapid manner, even in an emergency situation and under severe time pressure.

\section{Translaryngeal and transtracheal oxygenation and ventilation}

After an emergency placement of thin catheters through the cricothyroid liga- ment tracheal access can be achieved but due to the small lumen only a very limited possibility for ventilation is possible. By insufflation of oxygen at a high flow-rate into the trachea, according to the principle of apneic oxygenation [58] a diffusion oxygenation can be established. Problems inherent to this method of translaryngeal and transtracheal oxygenation are the often insufficient expiration and/or ventilation, followed by hypercarbia and the potential for barotrauma and a disruption in hemodynamics, particularly in the presence of closure of the supraglottic airway. The elimination of $\mathrm{CO}_{2}$ can be improved by systems which ensure expiration or an outflow of expirated air even with a fully obstructed upper airway [59-62].

\section{Strategies for management of the airway}

\section{Airway management levels}

Four levels of airway management are distinguished which allow opportunities for oxygenation or ventilation of the patient:

- Level 1: spontaneous respiration, assisted breathing or ventilation with a face mask

- Level 2: use of an extraglottic airway device (EGA)

- Level 3: placement of an endotracheal tube in the trachea

- Level 4: translaryngeal and transtracheal access

\section{Primary airway management with extraglottic airway devices}

The use of an EGA for primary airway management in elective interventions offers numerous advantages compared to ventilation by a face mask and in certain cases also compared to ventilation via an endotracheal tube. The use thus appears to be fundamentally indicated for certain routine procedures, provided there are no mitigating circumstances to the contrary ( $\bullet$ Table 4 ).

The use of so-called extended indications is currently controversially discussed. This refers primarily to the use of a larynx mask for a planned surgical procedure of $>2 \mathrm{~h}$, laparoscopic operations, patients with a body mass index (BMI) $>30 \mathrm{~kg} / \mathrm{m}^{2}$ and for surgery which is conducted with the patient in a prone position. In these cases the increased airway pressure and a potential aspiration hazard must be taken into account.

\section{Recommendation}

According to best available current evidence after weighing up the individual benefits and risks a laryngeal mask can be used as an alternative to the endotracheal tube with the extended indications. In these cases a second generation laryngeal mask airway should be used and a gastric tube should be advanced over the gastral lumen. After placement the position and tight seal shall be checked (see section "techniques for airway management").

\section{Management of expected difficult airways}

The basic procedure for managing the airway is governed by the question of whether an expected difficult airway is present: If in a specific case there are no predictors which are indicative of difficulties with mask ventilation, laryngoscopy and placement of the endotracheal tube, airway management will principally proceed after initiation of general anesthesia and when a sufficient level of anesthesia is achieved.

\section{Recommendation}

For the difficult airway an algorithm shall be available that is known to all personnel involved at the hospital and which covers the devices to be used and techniques to be mastered.

\section{Procedure for expected difficult airways}

An expected difficult airway can occur at all levels of airway management. The two techniques of mask ventilation and endo- 


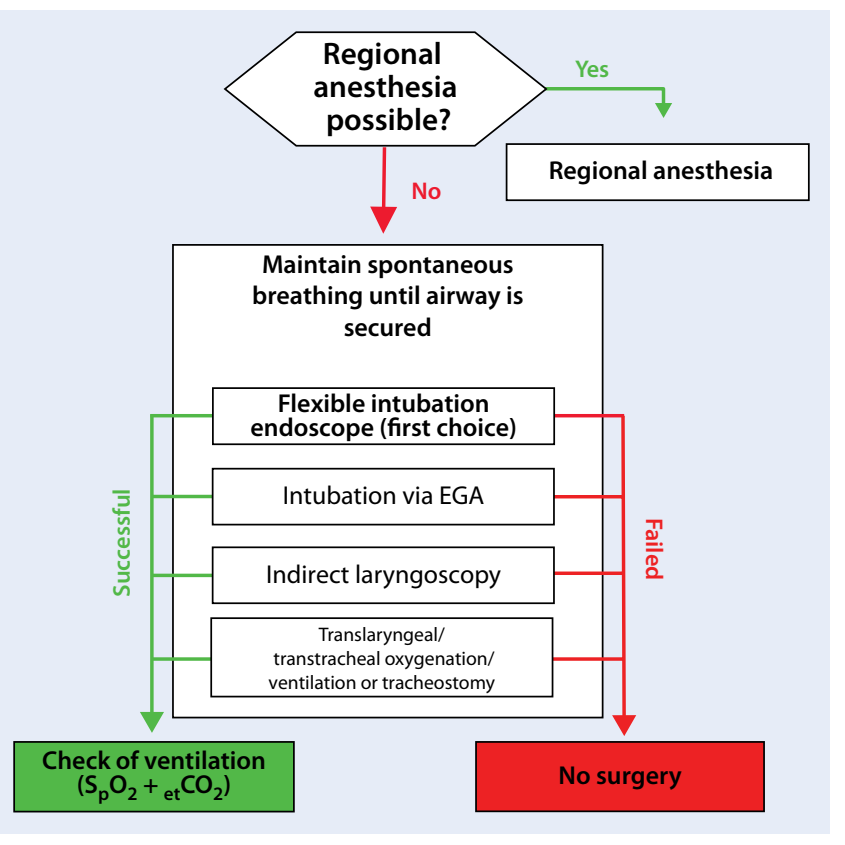

Fig. $1<$ Procedure for expected difficult airway

tracheal intubation are of pivotal importance in the evaluation of the airway.

\section{Recommendation}

In an expected difficult airway a regional anesthesia procedure shall primarily be considered.

\section{Recommendation}

If a regional anesthesia procedure is not possible and general anesthesia is required, if predictors are present or if there is a history for a difficult or impossible mask ventilation and/or endotracheal intubation, spontaneous breathing shall be maintained until the airway is secured.

Although the probability of a difficult airway increases with an increasing number of predictors, this procedure can also be necessary in the presence of only one predictor: typical examples are a very small mouth opening or a constricting subglottic tumor.

Principally, various techniques can be used when a difficult airway is expected.

\section{Recommendation}

The use of a flexible intubation endoscope has the greatest value; therefore, this instrument shall be available for management of the expected difficult airway and the anesthesiologist shall be trained in its correct handling.

A nasal or oral procedure can be selected depending on the patient circumstances.

\section{Recommendation \\ Spontaneous breathing shall be maintained until the endotracheal tube is securely placed in the trachea. With awake patients topical anesthesia of the airway shall be provided. Drug-induced sedation shall be dosed at the lowest possible level in order to prevent ap- nea and/or airway constriction.}

This technique of awake endoscopic intubation is associated with a very high success rate $[63,64]$.

Additional techniques described after sufficient local anesthesia or topical anesthesia of the airway are tracheotomy [65], establishment of a translaryngeal and/or transtracheal access, use of video laryngoscopy $[66,67]$ and placement of an EGA $[68,69]$ in awake, spontaneously breathing patients.

The algorithm "procedure for expected difficult airway" in the attachment to these recommendations depicts this in graphic format (• Fig. 1).

\section{Procedure for unexpected difficult airways}

Mask ventilation. Mask ventilation as the first level of airway management represents the basic technique for patient ventilation and is an important fallback option in the event of unexpected difficult airways. For example, it is used for oxygenation of the patient while additional material or assistance has to be obtained.

\section{Recommendation}

In the event of difficult mask ventilation in a sufficiently anesthetized patient, measures shall be implemented to elevate the base of tongue and thus to open the upper airway.

Among the simple means are the use of nasopharyngeal (e.g. Wendl tube) and/or oropharyngeal (e.g. Guedel tube) airways of adequate size.

\section{Recommendation}

In the absence of contraindications, the head shall be reclined and an Esmarch maneuver performed. A ventilation mask of appropriate size shall be held in both hands to obtain the best possible seal.

Ventilation can be performed by a second assistant or with an adequately adjusted ventilator using PCV.

\section{Recommendation}

If no neuromuscular blockade has been performed, this should be considered via a fast acting muscle relaxant (e.g. succinylcholine, rocuronium) $[27,29]$.

\section{Direct laryngoscopy}

If sufficient visibility of the glottis is not possible using direct laryngoscopy, then simple manipulation can improve this. Optimal external laryngeal manipulation (OELM) or backward upward rightward pressure (BURP) have been described as laryngeal manipulation maneuvers [70, 71]. If there are no contraindications, an optimum positioning of the head can be helpful by lifting and/or reclining [72, 73].

\section{Recommendation}

In the case of restricted view of the glottis despite appropriate manipulation maneuvers, the use of special tube insertion aids with soft, atraumatic tips can be considered $[74,75]$. The technique using a rigid stylet protruding from the endotracheal tube shall not be used. 


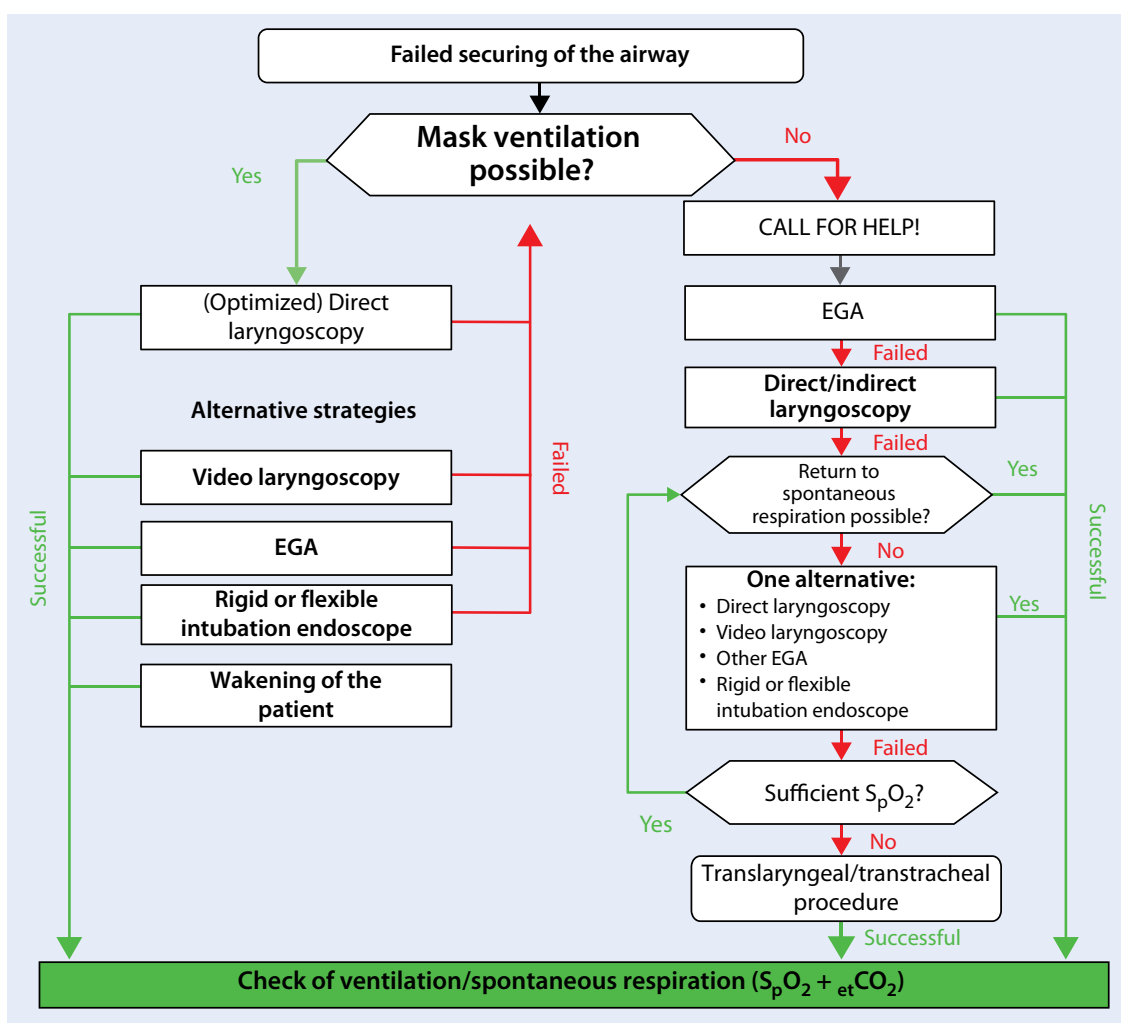

Fig. $2 \Delta$ Procedure for unexpected difficult airways

\section{Recommendation}

The number of intubation attempts with direct laryngoscopy shall be limited to a maximum of two.

The risk of significant life-threatening complications, such as severe hypoxia, regurgitation, aspiration, hypotension, bradycardia and cardiac arrest increases with each additional, unsuccessful intubation attempt [76-79].

\section{Recommendation}

In the event of an unexpected difficult airway after one unsuccessful intubation attempt a further attempt with direct laryngoscopy shall only be undertaken when measures have been taken to optimize the intubation conditions.

Among these measures to optimize intubation conditions are an improved position of the patient (head), suctioning of secretions to improve visibility and use of tube insertion aids and alternative blades. This also applies to situations when mask ventilation is possible. Repeated manipulation can lead to mucosal swelling so that tube will then often be possible [80]. suming [81].

\section{Extraglottic airway devices}

aid of a flexible intubation endoscope depending on the EGA used.

\section{Return to spontaneous respiration}

\section{Recommendation}

If securing the airway was unsuccessful even when sufficient oxygenation is possible (e.g. mask ventilation is possible) a return to spontaneous respiration should be considered. Depending on the medications used to induce general anesthesia, an antagonist or reversal shall be considered.

\section{Recommendation}

In the case of a "cannot intubate, cannot ventilate" situation, this option shall likewise be considered.

However, in the event of impossible oxygenation this procedure does not represent a reliable option, depending on the medication used to induce general anesthesia, even for immediate reversal of a neuromuscular block (e.g. sugammadex after rocuronium), as the actual time point of the return to spontaneous respiration cannot be predicted $[82,83]$.

\section{Translaryngeal and/or transtracheal access}

of video laryngoscopy today represents the most important method for management of an unexpected difficult airway, as after a primary unsuccessful attempt at direct intubation a correct placement of the

A rigid or flexible endoscopic intubation is likewise possible in an anesthetized patient with an unexpected difficult airway; however, compared to the procedure for an expected difficult airway the use of a flexible intubation endoscope is frequently more difficult and time-con-

The EGAs have an important role in the management of an unexpected difficult airway, as successful positioning can be possible even in the case of difficult mask ventilation and/or unsuccessful laryngoscopy. If intubation is urgently necessary, after successful placement of an EGA the intubation can proceed blindly or with the

\section{Recommendation}

If airway management fails at the first three levels and asphyxia occurs, oxygenation shall be performed via a translaryngeal and/or transtracheal access.

The invasiveness of this method or its (in a particular case uncertain) success should on no account be interpreted to the effect that an indicated cricothyrotomy is not to be done due to assumed safety aspects, as this is associated with even more fatal consequences (e.g. hypoxic brain damage or death).

\section{Algorithm for unexpected difficult airways}

In the attachment there is an algorithm for the "procedure for unexpected difficult airways". The procedure is illustrated graphically under consideration of the recommendations stated (• Fig. 2). 
Table 5 Minimum equipment for the anesthesiologists' workstation

\begin{tabular}{|c|c|}
\hline Level & Material and instruments \\
\hline $\begin{array}{l}\text { Attending patients with expected } \\
\text { difficult airways }\end{array}$ & Flexible intubation endoscope \\
\hline Level 1 & Face masks, Guedel and Wendl tubes, different sizes \\
\hline Level 2 & Extraglottic airway devices in different sizes \\
\hline \multirow[t]{3}{*}{ Level 3} & 1. Direct laryngoscope with blades in different sizes \\
\hline & $\begin{array}{l}\text { 2. Alternative instrument to conventional Macintosh laryn- } \\
\text { goscope (e.g. video laryngoscope) }\end{array}$ \\
\hline & 3. Tube insertion aids (e.g. stylets) \\
\hline Level 4 & Equipment for translaryngeal/transtracheal access \\
\hline Accessories & Apparatus and instruments as recommended by the DGAI \\
\hline
\end{tabular}

The algorithm begins with the situation "failed securing of the airway". Thus an immediate entry into the algorithm is possible without a long orientation phase. Further airway management is dependent on whether mask ventilation is possible or not. If sufficient oxygenation is possible with mask ventilation, there is no acute endangerment of the patient. In the case of unsuccessful intubation or placement of an EGA, additional promising techniques and instruments can be employed for airway management.

\section{Recommendation}

Given sufficient mask ventilation the alternative which has the greatest prospect of success shall be used, which is available in the particular situation and which the user has experience with. If these efforts also fail, then given sufficient mask ventilation further attempts at airway management can be implemented; however, any further attempts shall be carefully planned: If there is no prospect of success or if there is a danger of airway obstruction, such attempts shall be omitted and a return to spontaneous respiration shall be considered. After spontaneous breathing and/or awakening of the patient an alternative method can be selected analogous to the procedure for expected difficult airways.

If mask ventilation as a fallback option fails after a first intubation attempt or if it subsequently proves to be insufficient, a "cannot intubate, cannot ventilate" situation has occurred. This represents an acute danger of hypoxia for the patient.

Although the majority of unexpected difficult airway situations can be handled with the assistance of this algorithm, it cannot be transferred to every imaginable situation per se.

\section{Recommendation}

In the "cannot intubate, cannot ventilate" situation, assistance shall be obtained immediately. Owing to the lack of oxygenation very few attempts at airway management shall be carried out. An EGA shall be placed for oxygenation. If such placement has primarily failed a different size or an alternative EGA should be used. The method of video laryngoscopy has an important role in this situation. If lack of success continues a return to spontaneous breathing should be considered. If this is the case the patient shall be returned to spontaneous breathing or awakened. If this is not possible an attempt to secure the airway shall be carried out with another alternative device. In this case the device which has the best prospect of success shall be selected, which is immediately available and which the user has experience with in the given situation. In parallel with this a translaryngeal or transtracheal procedure shall be prepared. If this attempt also fails, given decreasing or insufficient oxygen saturation, the translaryngeal or transtracheal procedure shall be employed. Waking the patient and possibly another attempt at securing the airway can only be considered in the presence of good oxygenation.

\section{Recommendation}

An assessment of the airway (why does securing the airway fail?) and a check of vital parameters shall take place with each step of the algorithm and this step shall be skipped if there is no prospect of success or if asphyxia is imminent.

Every successful attempt at airway management ends with a check of ventilation or spontaneous respiration; nevertheless, it can be possible that further measures are required, e.g. if an imminent acute situation is mastered with the aid of an EGA, the subsequent placement of an endotra- cheal tube can still be necessary for various reasons.

\section{Securing the airway in patients with a risk of aspiration}

\section{Recommendation}

In patients with a high risk of aspiration the initiation of general anesthesia shall primarily occur without mask ventilation. If there are predictors of a difficult airway, the indications for intubation while maintaining spontaneous respiration should be permissively considered.

\section{Recommendation}

In the event of so-called rapid sequence induction (RSI, synonymous with rapid sequence intubation) after induction of general anesthesia and sufficient neuromuscular blocking without interim ventilation, endotracheal intubation shall be performed. In patients with an acute danger of hypoxia, pressure-limited interim ventilation or mechanical pressure-controlled ventilation can secure oxygenation [84].

The circumstances for application of cricoid pressure to prevent potential regurgitation of stomach contents in patients prone to aspiration are ambiguous. Some publications, for example indicate that cricoid pressure is frequently incorrectly applied [85] so that a reliable closure of the esophagus by cricoid pressure cannot regularly be achieved $[86,87]$ and muscle tone of the lower esophagus sphincter can be reduced by the maneuver [88]. In addition, the application of cricoid pressure can impede mask ventilation as well as direct and even indirect laryngoscopy [89]. On the other hand, compression of the esophagus is possible [90] so that a certain barrier to regurgitation does exist [91].

\section{Recommendation}

After weighing up the potential benefits and risks the routine application of cricoid pressure can be omitted. In individual cases, specifically under visual control, cricoid pressure can be helpful to reduce or to prevent regurgitation. In cases of difficult mask ventilation or difficult laryngoscopy, the cricoid pressure shall be released or terminated. 


\section{Table 6 Frequent causes for airway problems after extubation}

Edema or formation of secretion due to:

Manipulation of the airways, e.g. as part of a difficult airway management

Operations and procedures in the head-neck region

Bronchospasm

Respiratory insufficiency

Residual neuromuscular blockade

Bleeding in the region of the airway or the surrounding tissues

Emphysema formation due to (tension) pneumothorax or perforations in the region of trachea or esophagus

Table 7 Consensus classification

\begin{tabular}{|lll}
\hline Recommendation & Recommendation against an intervention & Description \\
\hline "Shall" & "Shall not"/"is not indicated" & Strong recommendation \\
\hline "Should" & "Should not" & Recommendation \\
\hline "Can"/"is uncertain" & "Can be omitted"/"is uncertain & No recommendation
\end{tabular}

Minimum equipment of anesthesiologists' workstation

\section{Recommendation}

Fundamentally at each anesthesiologist workstation the material and instruments, which allow airway management at each of the four levels for daily routine and also in emergency cases shall be readily at hand (- Table 5).

\section{Documentation and tracking}

\section{Recommendation}

The documentation of each airway management shall provide detailed information about any difficulties that occurred.

The auxiliary materials and instruments used for mask ventilation, airway management and intubation, even the best obtained view of the glottis and also the number of attempts until definitive securing of the airway shall be included in the documentation.

\section{Recommendation}

The classification by Cormack and Lehane shall also be used for video laryngoscopy.

The documentation should be detailed enough that at a later time point it will be clear which laryngoscopy findings were obtained with which device [92]. Likewise, it shall be documented whether an external manipulation (OELM or BURP) was carried out for the obtained findings and whether a stylet or other aid was required for successful intubation.

\section{Recommendation}

For future reference the tube size, cuff pressure, intubation depth, placement of a pharyngeal tamponade and any specific head positions should be documented.

\section{Recommendation}

After a difficult airway management, the circumstances and the method used to solve the problem shall be carefully documented in the anesthesia records. In addition, in this case a patient information sheet shall be provided in a generally understandable format. This document shall contain the point of time, the hospital and the type of problems and solutions in written form. The anesthesia problem card issued by the DGAI shall be used and provided to the patient together with the relevant information.

\section{Measures after securing the airway}

\section{Recommendation}

After successful airway management the correct position of the endotracheal tube and/or of the EGA shall be verified.

Reliable methods for use of an endotracheal tube are expiratory $\mathrm{CO}_{2}$ measurement via capnography and intubation under (direct or indirect) vision.

\section{Recommendation}

Auscultation of the thorax shall be performed to prevent an excessively deep position of the tube.

After an EGA has been inserted to an adequate depth, a typical capnography and flow curve, good sealing during ventilation and breathing sounds on both sides of the chest are indications of a correct position. Various tests have been described for a positional check of an EGA with gastric drainage channel (see section "techniques to secure the airway").

\section{Recommendation}

The cuff pressure shall be checked and adjusted as needed, both after placement of an endotracheal tube and an EGA.

There are no definitive studies on the administration of corticosteroids for prevention of laryngeal edema after difficult airway management or prolonged manipulation in the region of the larynx. The administration of a single dose $1 \mathrm{~h}$ before planned extubation is not effective $[93,94]$. On the contrary, several single doses beginning $12-24 \mathrm{~h}$ before extubation reduce the incidence of a post-extubation stridor $[95,96]$.

\section{Extubation after difficult airway management}

The extubation can be as equally critical as the intubation, especially after difficult airway management. Approximately one third of the difficult cases observed within the scope of airway management occur directly after extubation or in the subsequent waking phase [97]. Frequent causes for airway problems after extubation are provided in $\bullet$ Table 6 .

\section{Recommendations for extubation}

\section{Recommendation}

Before extubation, predictors for a difficult reintubation shall be recognized. In the case of possible problems, a clear strategy shall be followed for the planned difficult extubation. 


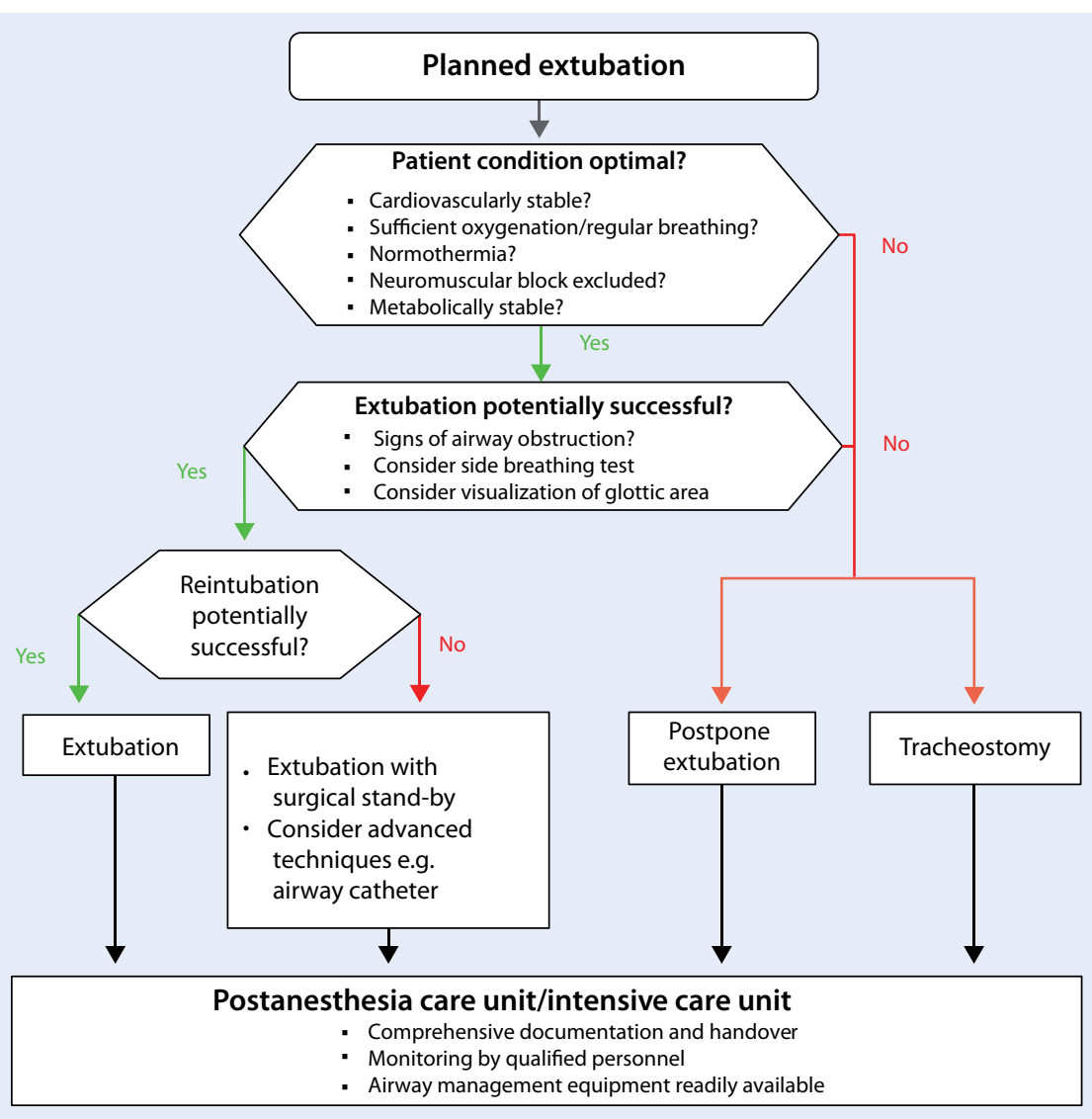

Fig. 3 ॥ Procedure for Planned Extubation

Depending on the patient and on the performed procedure, evaluation of the supraglottic region of the anesthetized patient can be useful before extubation. This can be done by means of video laryngoscopy.

\section{Recommendation}

The cuff leak test can be conducted to detect laryngeal edema.

To do this, unblock the cuff and determine the difference of inspiratory and expiratory tidal volume over the first six breaths. In the event of an (average) secondary air volume of more than $110 \mathrm{ml}$ per breath there is a low risk of a clinically relevant laryngeal edema [98].

The attendance of an ear nose and throat surgeon or of a maxillofacial surgeon can be immediately required. It may be necessary to prepare for a cricothyrotomy or tracheotomy. and to avoid a cough stimulus.

\section{Recommendation}

The monitoring of the extubated patient shall carried out by qualified personnel. Any newly occurring symptoms which indicate the occurrence of an airway complication, such as hoarseness, (increasing) swelling, difficulty
The "procedure for planned extubation" is shown in $\bullet$ Fig. 3.

\section{Education and training}

\section{Recommendation}

A thorough education and regular training shall be implemented to ensure successful management of unexpected and expected difficult airways.

In the case of problems with airway management, only the instruments and techniques which are regularly employed and are thus well-mastered on elective patients are promising for success.

\section{Recommendation}

A regular training on airway simulators should be implemented in translaryngeal and transtracheal techniques.

In addition, the identification and puncture of the cricothyroid ligament can be learnt by means of regular application of translaryngeal anesthesia for flexible endoscopic intubation under spontaneous breathing.

\section{Recommendation}

Training in the individual techniques should basically proceed in four steps:

- Acquisition of theoretical knowledge.

- Practicing of techniques and skills on airway simulators and phantom models.

- Use of the techniques under supervision on patients with an unremarkable airway. This shall continue until a reliable handling is ensured even in emergency situations.

In patients with expected difficulties during extubation owing to a hyperresponsive tracheobronchial system, in certain situations the endotracheal tube can be removed at an early stage and an EGA placed in order to assist with ventilation swallowing, chest pains and emphysema formation shall be detected at an early stage.
- Use of techniques under supervision on patients with difficult airways and regular use in the clinical routine.

\section{Core requirements}

1. For preoperative evaluation of the airtained and a clinical evaluation performed.

2. The following minimum requirements for management of the airway apply to every anesthesiology workplace: possibility for mask ventilation, availability of EGA, aids for direct laway the patient history shall be ob- 
ryngoscopy, alternatives to the Macintosh blade (e.g. video laryngoscope) and instruments for translaryngeal/ transtracheal oxygenation/ventilation.

3. In the presence of predictors or evidence in the patient history of a difficult or impossible mask ventilation and/or endotracheal intubation, the intubation shall take place on awake spontaneously breathing patients using a flexible intubation endoscope.

4. Second generation laryngeal mask airways should be employed when extended indications are present.

5. After placement of EGAs and sufficient ventilation the cuff pressure shall be checked and adjusted as needed. In general a pressure of $60 \mathrm{cmH}_{2} \mathrm{O}$ should not be exceeded.

6. In the event of an unexpected difficult airway the number of direct laryngoscopy attempts shall be limited to two.

7. Video laryngoscopy plays an important role in the management of unexpected difficult airways.

8. If intubation fails and oxygenation by other means fails, in the case of decreasing and/or insufficient oxygen saturation a translaryngeal or transtracheal access shall be established directly.

9. There shall be a clear strategy for any planned difficult extubation.

10. For successful management of unexpected and expected difficult airways, a thorough education and regular training shall be implemented and also an algorithm adapted to the particular clinical environment shall be available.

\section{Corresponding address}

\section{T. Piepho M.D.}

Department of Anesthesiology, University Medical Center of the Johannes Gutenberg-University-Mainz Langenbeckstr. 1, 55131 Mainz piepho@uni-mainz.de

\section{Compliance with ethical guidelines}

Conflict of interest. A. Timmermann, B. Zwissler, R. Noppens, T. Piepho, V. Dörges and E. Cavus are members of scientific medical societies and professional associations relevant to the development of the guidelines and elected representatives within the framework of the development of the guidelines. V. Dörges carries out remunerated activities as advisor or external reviewer and collaboration for a scientific advisory board in a corporation involved in health management (e.g. pharmaceutical industry, medical products industry), a commercially oriented contract research institute or an insurance company. C. Byhahn receives financial benefits (third-party funding) for research purposes or direct financing from employees of the institution associated with a corporation involved in health management, a commercially oriented contract research institute or an insurance company. E. Cavus receives professional fees for lecturing and teaching activities and remuneration for authorship or coauthorship on behalf of a corporation involved in health management, a commercially oriented contract research institute or an insurance company. T. Piepho, R. Noppens, B. Zwissler and A. Timmermann declare that there are no conflicts of interest.

This article does not contain studies on humans or animals.

\section{References}

1. Braun U, Goldmann K, Hempel V, Krier C (2004) [Airway Management. Guideline of the German Society for Anesthesiology and Intensive Care Medicine]. Anaesth Intensivmed 45:302-306

2. Timmermann A, Byhahn C, Wenzel V, Eich C, Piepho T, Bernhard M, Dörges V (2012) [Recommendation for the prehospital airwaymanagement]. Anaesth Intensivmed 53:294-308

3. Böttiger B, Bernhard M, Lier H, Fischer M, Schüttler J (2011) [Trauma-Update: S3 guideline polytrauma. What should the anesthesiologist know?]. Anaesth Intensivmed 52:S649-S656

4. Weiss M, Schmidt J, Eich C, Stelzner J, Trieschmann U, Müller-Lobeck L, Philippi-Höhne C, Becke K, Jöhr M, StraußJ (2011) [Recommendation for the prevention and treatment of the unexpected difficult airway in pediatric anesthesia]. Anaesth Intensivmed 52:S54-S63

5. Cormack RS, Lehane J (1984) Difficult tracheal intubation in obstetrics. Anaesthesia 39:1105-1111

6. Kheterpal S, Han R, Tremper KK, Shanks A, Tait AR, O'Reilly M, Ludwig TA (2006) Incidence and predic tors of difficult and impossible mask ventilation. Anesthesiology 105:885-891

7. Langeron O, Masso E, Huraux C, Guggiari M, Bianchi A, Coriat P, Riou B (2000) Prediction of difficult mask ventilation. Anesthesiology 92:1229-1236

8. Kheterpal S, Healy D, Aziz MF, Shanks AM, Freundlich RE, Linton F, Martin LD, Linton J, Epps JL, Fernandez-Bustamante A, Jameson LC, Tremper T, Tremper KK (2013) Multicenter Perioperative Outcomes Group (MPOG) Perioperative Clinical Research Committee. Incidence, predictors, and outcome of difficult mask ventilation combined with difficult laryngoscopy: a report from the multicenter perioperative outcomes group. Anesthesiology 119:1360-1369
9. Lavery GG, McCloskey BV (2008) The difficult airway in adult critical care. Crit Care Med 36:21632173

10. Adnet F, Racine SX, Borron SW, Clemessy JL, Fournier JL, Lapostolle F, Cupa M (2001) A survey of tracheal intubation difficulty in the operating room: a prospective observational study. Acta Anaesthesiol Scand 45:327-332

11. Samsoon GL, Young JR (1987) Difficult tracheal intubation: a retrospective study. Anaesthesia 42:487-490

12. Krobbuaban B, Diregpoke S, Kumkeaw S, Tanomsat M (2005) The predictive value of the height ratio and thyromental distance: four predictive tests for difficult laryngoscopy. Anesth Analg 101:15421545

13. Khan ZH, Kashfi A, Ebrahimkhani E (2003) A comparison of the upper lip bite test (a simple new technique) with modified Mallampati classification in predicting difficulty in endotracheal intubation: a prospective blinded study. Anesth Analg 96:595599

14. Reissell E, Orko R, Maunuksela EL, Lindgren L (1990) Predictability of difficult laryngoscopy in patients with long-term diabetes mellitus. Anaesthesia 45:1024-1027

15. Vani V, Kamath SK, Naik LD (2000) The palm print as a sensitive predictor of difficult laryngoscopy in diabetics: a comparison with other airway evaluation indices. J Postgrad Med 46:75-79

16. Wilson ME, Spiegelhalter D, Robertson JA, Lesser $P$ (1988) Predicting difficult intubation. Br J Anaesth 61:211-216

17. Shiga T, Wajima Z, Inoue T, Sakamoto A (2005) Predicting difficult intubation in apparently normal patients: a meta-analysis of bedside screening test performance. Anesthesiology 103:429-437

18. Arné J, Descoins P, Fusciardi J, Ingrand P, Ferrier B, Boudigues D, Ariès J (1998) Preoperative assessment for difficult intubation in general and ENT surgery: predictive value of a clinical multivariate risk index. Br J Anaesth 80:140-146

19. Pandit JJ, Duncan T, Robbins PA (2003) Total oxygen uptake with two maximal breathing techniques and the tidal volume breathing technique: a physiologic study of preoxygenation. Anesthesiology 99:841-846

20. Tanoubi I, Drolet P, Donati F (2009) Optimizing preoxygenation in adults. Can J Anaesth 56:449-466

21. Mort TC (2005) Preoxygenation in critically ill patients requiring emergency tracheal intubation. Crit Care Med 33:2672-2675

22. Dixon BJ, Dixon JB, Carden JR, Burn AJ, Schachter LM, Playfair JM, Laurie CP, O'Brien PE (2005) Preoxygenation is more effective in the 25 degrees head-up position than in the supine position in severely obese patients: a randomized controlled study. Anesthesiology 102:1110-1115

23. Altermatt FR, Munoz HR, Delfino AE, Cortinez LI (2005) Pre-oxygenation in the obese patient: effects of position on tolerance to apnoea. $\mathrm{Br} J \mathrm{An}$ aesth 95:706-709

24. Delay JM, Sebbane M, Jung B, Nocca D, Verzilli $D$, Pouzeratte Y, Kamel ME, Fabre JM, Eledjam JJ, Jaber $S$ (2008) The effectiveness of noninvasive positive pressure ventilation to enhance preoxygenation in morbidly obese patients: a randomized controlled study. Anesth Analg 107:1707-1713

25. Baillard C, Fosse JP, Sebbane M, Chanques G, Vincent F, Courouble P, Cohen Y, Eledjam JJ, Adnet F, Jaber S (2006) Noninvasive ventilation improves preoxygenation before intubation of hypoxic patients. Am J Respir Crit Care Med 174:171-177 
26. Byhahn C, Dorges V, Graf BM (2012) [Mask ventilation before relaxation. From dogma to individuality]. Anaesthesist 61:397-398

27. Jacomet A, Schnider T (2012) [Mandatory mask ventilation before relaxation. Where is the evidence?]. Anaesthesist 61:401-406

28. Warters RD, Szabo TA, Spinale FG, DeSantis SM, Reves JG (2011) The effect of neuromuscular blockade on mask ventilation. Anaesthesia 66:163-167

29. Ikeda A, Isono S, Sato Y, Yogo H, Sato J, Ishikawa T, Nishino T (2012) Effects of muscle relaxants on mask ventilation in anesthetized persons with normal upper airway anatomy. Anesthesiology 117:487-493

30. Seet E, Yousaf F, Gupta S, Subramanyam R, Wong DT, Chung F (2010) Use of manometry for laryngeal mask airway reduces postoperative pharyngolaryngeal adverse events: a prospective, randomized trial. Anesthesiology 112:652-657

31. Chantzara G, Stroumpoulis K, Alexandrou N, Kokkinos L, lacovidou N, Xanthos T (2014) Influence of LMA cuff pressure on the incidence of pharyngolaryngeal adverse effects and evaluation of the use of manometry during different ventilation modes: a randomized clinical trial. Minerva Anestesiol 80:547-555

32. Stix MS, O'Connor CJ Jr (2003) Depth of insertion of the ProSeal laryngeal mask airway. Br J Anaesth 90:235-237

33. Mahajan R, Batra YK (2009) Water bubble test to detect malposition of PLMA. J Anesth 23:634-635

34. Cook TM, Silsby J, Simpson TP (2005) Airway rescue in acute upper airway obstruction using a ProSeal Laryngeal mask airway and an Aintree catheter: a review of the ProSeal Laryngeal mask airway in the management of the difficult airway. Anaesthesia 60:1129-1136

35. Heard AM, Lacquiere DA, Riley RH (2010) Manikin study of fibreoptic-guided intubation through the classic laryngeal mask airway with the Aintree intubating catheter vs the intubating laryngeal mask airway in the simulated difficult airway. Anaesthesia 65:841-847

36. Blair EJ, Mihai R, Cook TM (2007) Tracheal intubation via the Classic and Proseal laryngeal mask airways: a manikin study using the Aintree Intubating Catheter. Anaesthesia 62:385-387

37. Piepho T, Fortmueller K, Heid FM, Schmidtmann I, Werner C, Noppens RR (2011) Performance of the C-MAC video laryngoscope in patients after a limited glottic view using Macintosh laryngoscopy. Anaesthesia 66:1101-1105

38. Aziz MF, Healy D, Kheterpal S, Fu RF, Dillman D, Brambrink AM (2011) Routine clinical practice effectiveness of the Glidescope in difficult airway management: an analysis of 2,004 Glidescope intubations, complications, and failures from two institutions. Anesthesiology 114:34-41

39. Cavus E, Neumann T, Doerges V, Moeller T, Scharf E, Wagner K, Bein B, Serocki G (2011) First clinical evaluation of the C-MAC D-Blade videolaryngoscope during routine and difficult intubation. Anesth Analg 112:382-385

40. Noppens RR, Mobus S, Heid F, Schmidtmann I, Werner C, Piepho T (2010) Evaluation of the McGrath Series 5 videolaryngoscope after failed direct laryngoscopy. Anaesthesia 65:716-720

41. Cavus E, Bein B, Doerges V (2011) [Airwaymanagement-Atemwegsmanagement-videoassisted techniques]. Anasthesiol Intensivmed Notfallmed Schmerzther 46:588-596
42. Noppens RR, Werner C, Piepho T (2010) [Indirect laryngoscopy: alternatives to securing the airway]. Anaesthesist 59:149-161

43. Herbstreit F, Fassbender $\mathrm{P}$, Haberl H, Kehren $\mathrm{C}$, Peters J (2011) Learning endotracheal intubation using a novel videolaryngoscope improves intubation skills of medical students. Anesth Analg 113:586-590

44. Bein B, Yan M, Tonner PH, Scholz J, Steinfath M, Doerges $V$ (2004) Tracheal intubation using the Bonfils intubation fibrescope after failed direct laryngoscopy. Anaesthesia 59:1207-1209

45. Halligan M, Charters P (2003) A clinical evaluation of the Bonfils Intubation Fibrescope. Anaesthesia 58:1087-1091

46. Falcetta S, Pecora L, Orsetti G, Gentili P, Rossi A, Gabbanelli V, Adrario E, Donati A, Pelaia P (2012) The Bonfils fiberscope: a clinical evaluation of its learning curve and efficacy in difficult airway management. Minerva Anestesiol 78:176-184

47. Aneeshkumar MK, Jones TM, Birchall MA (2009) A new indicator-guided percutaneous emergency cricothyrotomy device: in vivo study in man. Eur Arch Otorhinolaryngol 266:105-109

48. Eisenburger $P$, Laczika $K$, List $M$, Wilfing $A$, Losert $H$, Hofbauer R, Burgmann $\mathrm{H}$, Bankl H, Pikula B, Benumof JL, Frass M (2000) Comparison of conventional surgical versus Seldinger technique emergency cricothyrotomy performed by inexperienced clinicians. Anesthesiology 92:687-690

49. Johnson DR, Dunlap A, McFeeley P, Gaffney J, Busick B (1993) Cricothyrotomy performed by prehospital personnel: a comparison of two techniques in a human cadaver model. Am J Emerg Med 11:207-209

50. Schober P, Hegemann MC, Schwarte LA, Loer SA, Noetges $P$ (2009) Emergency cricothyrotomy-a comparative study of different techniques in human cadavers. Resuscitation 80:204-209

51. Murphy C, Rooney SJ, Maharaj CH, Laffey JG, Harte BH (2011) Comparison of three cuffed emergency percutaneous cricothyroidotomy devices to conventional surgical cricothyroidotomy in a porcine model. Br J Anaesth 106:57-64

52. Fikkers $B G$, van Vugt $S$, van der Hoeven JG, van den Hoogen FJ, Marres HA (2004) Emergency cricothyrotomy: a randomised crossover trial comparing the wire-guided and catheter-over-needle techniques. Anaesthesia 59:1008-1011

53. Keane MF, Brinsfield KH, Dyer KS, Roy S, White D (2004) A laboratory comparison of emergency percutaneous and surgical cricothyrotomy by prehospital personnel. Prehosp Emerg Care 8:424-426

54. Mariappa V, Stachowski E, Balik M, Clark P, Nayyar V (2009) Cricothyroidotomy: comparison of three different techniques on a porcine airway. Anaesth Intensive Care 37:961-967

55. Metterlein T, Frommer M, Ginzkey C, Becher J, Schuster F, Roewer N, Kranke P (2011) A randomized trial comparing two cuffed emergency cricothyrotomy devices using a wire-guided and a catheter-over-needle technique. J Emerg Med 41:326332

56. Bair AE, Panacek EA, Wisner DH, Bales R, Sakles JC (2003) Cricothyrotomy: a 5-year experience at one institution. J Emerg Med 24:151-156

57. Dillon JK, Christensen B, Fairbanks T, Jurkovich G, Moe KS (2013) The emergent surgical airway: cricothyrotomy vs. tracheotomy. Int J Oral Maxillofac Surg 42:204-208

58. Frumin MJ, Epstein RM, Cohen G (1959) Apneic oxygenation in man. Anesthesiology 20:789-798
59. Preussler NP, Schreiber T, Huter L, Gottschall R, Schubert H, Rek H, Karzai W, Schwarzkopf K (2003) Percutaneous transtracheal ventilation: effects of a new oxygen flow modulator on oxygenation and ventilation in pigs compared with a hand triggered emergency jet injector. Resuscitation 56:329-333

60. Hamaekers AE, Borg PA, Enk D (2012) Ventrain: an ejector ventilator for emergency use. Br J Anaesth 108:1017-1021

61. Hamaekers AE, Borg PA, Goetz T, Enk D (2011) Ventilation through a small-bore catheter: optimizing expiratory ventilation assistance. $\mathrm{Br} \mathrm{J}$ Anaesth 106:403-409

62. Hamaekers AE, van der Beek T, Theunissen M, Enk D (2015) Rescue ventilation through a small-bore transtracheal cannula in severe hypoxic pigs using expiratory ventilation assistance. Anesth Analg 120:890-894

63. Ovassapian A, Dykes MH, Golmon ME (1983) A training programme for fibreoptic nasotracheal intubation. Use of model and live patients. Anaesthesia 38:795-798

64. Fuchs G, Schwarz G, Baumgartner A, Kaltenbock F, Voit-Augustin H, Planinz W (1999) Fiberoptic intubation in 327 neurosurgical patients with lesions of the cervical spine. J Neurosurg Anesthesiol 11:11-16

65. Thomson S (1905) Tracheotomy under local anaesthesia. Br Med J 2:922-923

66. Moore AR, Schricker T, Court O (2012) Awake videolaryngoscopy-assisted tracheal intubation of the morbidly obese. Anaesthesia 67:232-235

67. Rosenstock CV, Thogersen B, Afshari A, Christensen AL, Eriksen C, Gatke MR (2012) Awake fiberoptic or awake video laryngoscopic tracheal intubation in patients with anticipated difficult airway management: a randomized clinical trial. Anesthesiology 116:1210-1216

68. Lee MC, Absalom AR, Menon DK, Smith HL (2006) Awake insertion of the laryngeal mask airway using topical lidocaine and intravenous remifentanil. Anaesthesia 61:32-35

69. Dhar P, Osborn I, Brimacombe J, Meenan M, Linton $P$ (2001) Blind orotracheal intubation with the intubating laryngeal mask versus fibreoptic guided orotracheal intubation with the Ovassapian airway. A pilot study of awake patients. Anaesth Intensive Care 29:252-254

70. Benumof JL, Cooper SD (1996) Quantitative improvement in laryngoscopic view by optimal external laryngeal manipulation. J Clin Anesth 8:136-140

71. Takahata O, Kubota M, Mamiya K, Akama Y, Nozaka T, Matsumoto H, Ogawa H (1997) The efficacy of the "BURP" maneuver during a difficult laryngoscopy. Anesth Analg 84:419-421

72. Levitan RM, Mechem CC, Ochroch EA, Shofer FS, Hollander JE (2003) Head-elevated laryngoscopy position: improving laryngeal exposure during laryngoscopy by increasing head elevation. Ann Emerg Med 41:322-330

73. Schmitt HJ, Mang H (2002) Head and neck elevation beyond the sniffing position improves laryngeal view in cases of difficult direct laryngoscopy. J Clin Anesth 14:335-338

74. Gataure PS, Vaughan RS, Latto IP (1996) Simulated difficult intubation. Comparison of the gum elastic bougie and the stylet. Anaesthesia 51:935-938

75. Jabre $P$, Combes $X$, Leroux B, Aaron E, Auger H, Margenet A, Dhonneur G (2005) Use of gum elastic bougie for prehospital difficult intubation. Am J Emerg Med 23:552-555 
76. Rose WD, Anderson LD, Edmond SA (1994) Analysis of intubations. Before and after establishment of a rapid sequence intubation protocol for air medical use. Air Med J 13:475-478

77. Mort TC (2004) The incidence and risk factors for cardiac arrest during emergency tracheal intubation: a justification for incorporating the ASA Guidelines in the remote location. J Clin Anesth 16:508-516

78. Martin LD, Mhyre JM, Shanks AM, Tremper KK, Kheterpal S (2011) 3,423 emergency tracheal intubations at a university hospital: airway outcomes and complications. Anesthesiology 114:42-48

79. Hasegawa K, Shigemitsu K, Hagiwara Y, Chiba T, Watase H, Brown CA 3rd, Brown DF (2012) Japanese Emergency Medicine Research Alliance Investigators. Association between repeated intubation attempts and adverse events in emergency departments: an analysis of a multicenter prospective observational study. Ann Emerg Med 60:749754

80. Paolini JB, Donati F, Drolet P (2013) Review article: video-laryngoscopy: another tool for difficult intubation or a new paradigm in airway management? Can J Anaesth 60:184-191

81. Delaney KA, Hessler R (1988) Emergency flexible fiberoptic nasotracheal intubation: a report of 60 cases. Ann Emerg Med 17:919-926

82. Ortiz-Gomez JR, Palacio-Abizanda FJ, Fornet-Ruiz I (2014) Failure of sugammadex to reverse rocuronium-induced neuromuscular blockade: a case report. Eur J Anaesthesiol 31:708-709

83. Curtis R, Lomax S, Patel B (2012) Use of sugammadex in a 'can't intubate, can't ventilate' situation. $\mathrm{Br}$ J Anaesth 108:612-614

84. Lawes EG, Campbell I, Mercer D (1987) Inflation pressure, gastric insufflation and rapid sequence induction. Br J Anaesth 59:315-318

85. Clark RK, Trethewy CE (2005) Assessment of cricoid pressure application by emergency department staff. Emerg Med Australas 17:376-381

86. Smith KJ, Dobranowski J, Yip G, Dauphin A, Choi PT (2003) Cricoid pressure displaces the esophagus: an observational study using magnetic resonance imaging. Anesthesiology 99:60-64

87. Boet S, Duttchen K, Chan J, Chan AW, Morrish W, Ferland A, Hare GM, Hong AP (2012) Cricoid pressure provides incomplete esophageal occlusion associated with lateral deviation: a magnetic resonance imaging study. J Emerg Med 42:606-611

88. Garrard A, Campbell AE, Turley A, Hall JE (2004) The effect of mechanically-induced cricoid force on lower oesophageal sphincter pressure in anaesthetised patients. Anaesthesia 59:435-439

89. Hocking G, Roberts FL, Thew ME (2001) Airway obstruction with cricoid pressure and lateral tilt. Anaesthesia 56:825-828

90. Zeidan AM, Salem MR, Mazoit JX, Abdullah MA, Ghattas T, Crystal GJ (2014) The effectiveness of cricoid pressure for occluding the esophageal entrance in anesthetized and paralyzed patients: an experimental and observational glidescope study. Anesth Analg 118:580-586

91. Rice MJ, Mancuso AA, Gibbs C, Morey TE, Gravenstein N, Deitte LA (2009) Cricoid pressure results in compression of the postcricoid hypopharynx: the esophageal position is irrelevant. Anesth Analg 109:1546-1552

92. Cavus E, Doerges V (2014) Glottic visualisation with videolaryngoscopy: proposal for a modified, indexed Cormack-Lehane Score [E-letter]. Br J Anaesth http://bja.oxfordjournals.org:80/cgi/qa-display/brjana_forum;1
93. Gaussorgues P, Boyer F, Piperno D, Gerard M, Leger P, Robert D (1988) Do corticosteroids prevent postextubation laryngeal edema? Prospective study of 276 adults. Crit Care Med 16:649

94. Ho LI, Harn HJ, Lien TC, Hu PY, Wang JH (1996) Postextubation laryngeal edema in adults. Risk factor evaluation and prevention by hydrocortisone. Intensive Care Med 22:933-936

95. Lee CH, Peng MJ, Wu CL (2007) Dexamethasone to prevent postextubation airway obstruction in adults: a prospective, randomized, double-blind, placebo-controlled study. Crit Care 11:R72

96. Francois B, Bellissant E, Gissot V, Desachy A, Normand S, Boulain T, Brenet O, Preux PM, Vignon $P$ Association des Réanimateurs du Centre-Ouest (ARCO) (2007) 12-h pretreatment with methylprednisolone versus placebo for prevention of postextubation laryngeal oedema: a randomised double-blind trial. Lancet 369:1083-1089

97. Cook TM, Woodall N, Frerk C (2011) Fourth National Audit Project. Major complications of airway management in the UK: results of the Fourth National Audit Project of the Royal College of Anaesthetists and the Difficult Airway Society. Part 1: anaesthesia. Br J Anaesth 106:617-631

98. Miller RL, Cole RP (1996) Association between reduced cuff leak volume and postextubation stridor. Chest 110:1035-1040 